Erratum

\title{
Long-Term $d$-Amphetamine in Rats: Lack of Change in Post-Synaptic Dopamine Receptor Sensitivity
}

David M. Jackson, Ruth C. Bailey, Macdonald J. Christie, Eva A. Crisp, and John H. Skerritt

Psychopharmacology (1981) 73:276-280

Because of an oversight in preparing the corrected manuscript, a 'note added in proof' was omitted from the paper by Jackson et al. [Psychopharmacology (1981) 73:276-280]. The content of the 'note' was as follows:

Because chronic amphetamine administration to rats has been reported to decrease striatal GABA concentrations, we investigated the effects of similar pretreatments to those used in the present paper on high and low affinity GABA binding sites in striatum according to the method of Skerritt et al. (1981). Using GABA concentrations of 28.8 and $299 \mathrm{nM}$, the binding ( $\mathrm{pmol} / \mathrm{mg}$ protein) in vehicle-pretreated animals was $0.678 \pm 0.040$ and $1.60 \pm 0.17$ respectively, and in $d$-amphetamine pretreated animals, $0.656 \pm 0.061$ and $1.76 \pm 0.19$ respectively. Thus, chronic $d$-amphetamine pretreatment of rats did not change significantly the number of high and low affinity GABA binding sites in the striatum, and such changes therefore are also unlikely to underlie the behavioural alteration reported in this communication. 